УДК 82.091

DOI: $10.17223 / 24099554 / 5 / 9$

\title{
О.Н. Болотникова
}

\section{ДОМ, ДВЕРЬ И ОКНО В «ВЕЧЕРАХ НА ХУТОРЕ БЛИЗ ДИКАНЬКИ» ГОГОЛЯ И ВОСТОЧНОСЛАВЯНСКАЯ СЕМИОТИКА ЖИЛИЩА}

\begin{abstract}
Статья посвящена гоголевской мифопоэтике дома, рассматриваемой в контексте восточнославянской обрядовой культуры. В «Вечерах на хуторе близ Диканьки» отчетливо отразились космогонические, сочиальные и коммуникативные аспекты смыслов, связанные со структурированием домашнего пространства. В космологическом плане дом выступает точкой пересечения вертикальной, связывающей небо и преисподнюю, и горизонтальной, освоенной человеком, оси мироздания. С сочиальной точки зрения дом структурирует организацию семьи как общественной группь, с информационной - служит местом общения и передачи родовой памяти. В пределах данных семиотических ракурсов в статье рассматриваются функиии лиминальных мотивов, ассоциируемых в гоголевском нарративе с окном и дверью.

Ключевые слова: мифопоэтика, восточнославянская семиотика жилища, Н.В. Гоголь, «Вечера на хуторе близ Диканьки», домамнее пространство, дверь, окно.
\end{abstract}

Для изучения семантики и поэтики домашних пространственных образов большую значимость имеет контекст традиции. Дом, будучи феноменом массовой материальной культуры, воплощает в себе в первую очередь систему коллективных представлений о «правильной» для данного сообщества организации быта, включающей в себя отношения к природному, социальному и информационному пространству. Эти презумпции даже в посттрадиционалистской культуре оказывают сильнейшее воздействие на индивидуальное художественное моделирование домашних образов, в большинстве случаев сохраняющих тесную связь с формами социально-бытового уклада определенного народа и исторической эпохи. В случае Н.В. Гоголя, писателя бикультурного и сложного в плане эстетики, таких порождающих традиций было несколько: во-первых, украинская бытовая культура и ее фольклорно-обрядовые представления; во-вторых, тесно с ней связанное барочное наследие, сохранявшее в Малорос- 
сии актуальность до конца XVIII в., в-третьих, как результат имперской ассимиляции, - формы домашнего уклада русской усадебной культуры и преломляющая их литературная символика вначале сентиментального горацианства, а затем романтического и раннереалистического жизнестроительства.

Исходным моментом здесь выступили фольклорно-мифологические представления, отражающие статус и функции дома и его отдельных элементов в рамках восточнославянской обрядовой культуры. Для Гоголя они были, с одной стороны, частью повседневного мира малороссийского мелкопоместного дворянина, а с другой предметом уже дистанцированного этнографического изучения, чтения казацких дум, знакомства с обрядами и поверьями ${ }^{1}$. Интерес к этой стороне народного быта, на сей раз уже великорусского, писатель сохранил надолго, свидетельством чему является запись конца 1840-х гг. «О крестьянском жилище» [5. С. 432-435].

Семиотика восточнославянского дома - хорошо изученная область этнографии и фольклористики, становившаяся предметом работ О.М. Фрейденберг, Т.В. Цивьян, В.Н. Топорова, Л.Г. Невской, Н.А. Криничной, А.Б. Мороз, С.М. Толстой и ряда других исследователей. Наиболее систематичное ее рассмотрение предпринял А.К. Байбурин, сосредоточившись в монографии «Жилище в обрядах и представлениях восточных славян» на ритуальнобытовом воплощении домашней пространственной семиотики [6]. В «высокой» культуре в дальнейшем эти коды потеряли связь с обрядовыми формами, но сохранили свою семиотическую значимость. Важнейшие функции дома в рамках фольклорно-мифологических представлений заключаются, по мнению А.К. Байбурина, в моделировании следующих мировоззренческих ориентаций: космологической, социальной и информационной. В статье мы сосредоточимся преимущественно на двух последних, менее изученных, смысловых планах.

Основой первого гоголевского цикла стала мифопоэтическая картина мира, восходящая к фольклорным представлениям восточных славян. Безусловно, в ее моделировании и повествовательном представлении писатель испытал глубокое воздействие барочной эмблематики, мистико-религиозной традиции и романтической сим-

${ }^{1}$ Об этнографическом кругозоре Гоголя и фольклорных влияниях в его творчестве см.: [1; 2. С. 249-291; 3; 4]. 
волизации ${ }^{2}$, но сколь бы глубоко ни трансформировалась исходная фольклорно-мифологическая семантика, ее организующая роль оставалась неизменной. Как констатировала одна из исследователей, Гоголь создал «фольклорно-мифологический универсум, который парадоксальным образом вписывается в систему представлений европейского средневековья, преломляясь при этом через сознание писателя XIX века» [13. С. 57].

В частности, в «Вечерах на хуторе близ Диканьки» отчетливо отразились социальные аспекты смыслов, связанные со структурированием пространства. Его центром и моделью является в «Вечерах» жилище, в чьем описании «Гоголь стремится почти что к этнографической точности» [14. С. 195]. Его особая роль проявляется уже в предисловии Рудого Панька, для которого заочное знакомство с читателем становится поводом для приглашение в гости и посещения хаты. Мышление «домашними» категориями для него столь естественно, что даже неловкость своего положения автора-дилетанта ${ }^{3}$ он объясняет, используя домашнюю метафорику: «Это все равно, как, случается, иногда зайдешь в покои великого пана: все обступят тебя и пойдут дурачить» ${ }^{4}$ [16. С. 103]. Хата - это средоточие жизни, место бытовых забот и отдохновения («у нас, на хуторах, водится издавна: как только окончатся работы в поле, мужик залезет отдыхать на всю зиму на печь» [16. С. 104]), здесь собираются гости и рассказываются истории («Бывало, соберутся, накануне праздничного дня, добрые люди в гости, в пасичникову лачужку, усядутся за стол, - и тогда прошу только слушать» [16. С. 104]), здесь чаще всего завязываются и разрешаются главные события, сюда настойчиво пытается вернуться любой герой, выпил ли он лишнего, как Каленик в «Майской ночи», или его водит нечистая сила, как деда в «Заколдованном месте».

Особую роль жилища Гоголь подчеркивает уже на уровне описания, которое, вполне сохраняя конкретность, насыщается социально-характерологическими и/или космологическими значениями: оно помогает ввести читателя в мир героя, а самого персонажа позиционировать в универсальном мифологическом пространстве. Так, воинственный и прямой характер пана Данилы в повести «Страшная

${ }^{2}$ Из важнейших работ по этой теме см.: [7. С. 585-600; 8. С. 324-328; 9. С. 7-99; 10. C. $70-188 ; 11$. C. $52-80 ; 12$. C. $127-186,249-292]$.

${ }^{3}$ О значении маски дилетанта в литературе эпохи см.: [15. С. 13-24].

${ }^{4}$ Здесь и далее все выделения в тексте цитат принадлежат автору статьи. 
месть» вполне передает обстановка его жилища, наполовину семейное пристанище, наполовину казацкий курень:

Невысокие у него хоромы: хата на вид, как и у простых козаков, и в ней одна светлица; но есть где поместиться там и ему, и жене его, и старой прислужнице, и десяти отборным молодцам. Вокруг стен вверху идут дубовые полки. Густо на них стоят миски, горшки для трапезы. Есть меж ними и кубки серебряные, и чарки, оправленные в золото, дарственные и добытые на войне. Ниже висят дорогие мушкеты, сабли, пищали, копья. <...> Под стеною, внизу, дубовые, гладко вытесанные лавки. Возле них, перед лежанкою, висит на веревках, продетых в кольцо, привинченное к потолку, люлька. Во всей светлице пол гладко убитый и смазанный глиною. На лавках спит с женою пан Данило. На лежанке старая прислужница. В люльке тешится и убаюкивается малое дитя. На полу покотом ночуют молодцы [16. С. 249-250].

Бытовая утварь, люлька, место сна служанки и хозяев связывают дом со сферой повседневных забот и гендерно-социальным разделением, воинские доспехи и оружие, спящие на полу казаки вписывают его в стилизованное историческое пространство.

Совершенно по-иному выглядит замок колдуна, где быт отсутствует, а вся обстановка подчеркивает инфернальный характер жилища - хода в «чужой», запредельный мир. Как констатировала Е.Л. Березович, «пространственная вертикаль, соединяющая земной мир с небесным, неоднородна и не может быть освоена человеком, “закрепленным” в ее средней точке» [17. С. 43]. У Гоголя инобытийное пространство тоже является чужим и чаще всего репрезентируется в остраняющем восприятии героя/повествователя. Именно так, в зловеще освещенное окно, т.е. извне, видит пан Данило, взобравшийся по высокому дубу, аналогу мирового древа, интерьер этой дьявольской обители:

Присевши на сук, возле самого окна, уцепился он рукою за дерево, и глядит: в комнате и свечи нет, а светит. По стенам чудные знаки. Висит оружие, но все странное: такого не носят ни турки, ни крымцы, ни ляхи, ни християне, ни славный народ шведский. Под потолком взад и вперед мелькают нетопыри, и тень от них мелькает по стенам, по дверям, по помосту. Вот отворилась без скрыпа дверь. <..>> Это он, это тесть! <..> Тут поставил он на стол горшок и начал кидать в него какие-то травы [16. С. 256-257]. 
В космологическом плане дом в «Вечерах» выступает точкой пересечения вертикальной, связывающей небо и преисподнюю, и горизонтальной, социально-бытовой, организации пространства. Как заметил Ю.М. Лотман, подобный параллелизм смысловых планов в отдельных локусах проявляется отчетливо и становится сюжетообразующим, как в описании дома сотника в «Майской ночи» [18. С. 633]. В видении сонного Левко заброшенный панский дом трансформируется. Первоначально он предстает тронутым разрушением, заросшим мхом и травой, с закрытыми ставнями. Но в отражении облик дома меняется, как бы возвращаясь к своей изначальной природе: «старинный господский дом, опрокинувшись вниз, виден был в пруду чист и в каком-то ясном величии» [16. С. 174]. Отойдя вдаль и вновь вглядываясь в дом, Левко думает: «Дом новехонький; краски живы, как будто сегодня он выкрашен. Тут живет кто-нибудь» [16. C. 174].

Показательно, что обжитость дома связывается в видении Левко еще и с окнами, которые отворяются и показывают манящий образ девушки. По наблюдениям В.Н. Топорова, «окно - одно из важных условий любовного свидания, демонстрации женщиной своих прелестей» [19. С. 175] $]^{5}$. Этот мотив «девы у окна», восходящий к мифопоэтике культов плодородия, отразившийся в сказочных сюжетах похищения из окна и приобретший трансцендентный смысл в поэтике романтизма ${ }^{6}$, дублирует сцену тайного свидания Левко и Ганны и служит прологом к волшебному сюжету повести:

Вместо мрачных ставней глядели веселые стеклянные окна и двери. <...> И вот почудилось, будто окно отворилось. Притаивши дух, не дрогнув и не спуская глаз с пруда, он, казалось, переселился в глубину его и видит: наперед белый локоть выставился в окно, потом выглянула приветливая головка с блестящими очами, тихо светившими сквозь темнорусые волны волос, и оперлась на локоть. И видит: она качает слегка головою, она машет, она усмехается... Сердце его разом забилось... Вода задрожала, и окно закрылось снова» [16. С. 174].

Подобные смысловые смещения мы встретим и в бытовом контексте, например в «Сорочинской ярмарке», где меняется уже внутреннее пространство дома, когда Параска смотрится в зеркало (ана-

\footnotetext{
${ }^{5}$ См. также: [20. С. 251-256].

${ }^{6} \mathrm{O}$ судьбе мотива в романтическую эпоху см. нашу статью [21].
} 
лог окна), «наклоняясь к нему головою». Она видит «под собою, вместо полу, потолок с накладенными под ним досками <...> и полки, уставленные горшками» [16. С. 134]. Верх и низ в отражении поменялись местами, создавая возможность трансформации пространства и прочитывания его в космологическом плане, что в повествовательной структуре повести сочетается с карнавальным обыгрыванием демонических сюжетов [22. С. 24-34]. И вновь контекст этого эпизода определяют матримониальные и бытовые замыслы: Параска мечтает о женихе, о создании семьи и нового дома («перейдем жить в новую хату» [16. С. 134].

В «Вечерах», сохраняя базовые восточнославянские представления, дом является пространством, структурирующим социально-коммуникативные связи. С социальной точки зрения дом - это, прежде всего, род, семья, о чем свидетельствует даже современное бытовое словоупотребление («дружить домами»). Тем самым структура домашнего пространства отражает внутреннюю организацию семьи как общественной группы. В восточнославянском традиционном жилище выделяются в соответствии с гендерными, возрастными и властными отношениями мужская и женская («бабий угол») зоны, локусы старших и младших, место хозяина, спроецированные на иерархию сакрального пространства, на сей раз горизонтальную (ближе или дальше от центра - красного угла). В частности, «поэтому обряды, совершаемые при строительстве дома, можно с равным основанием рассматривать как обряды, посвященные созданию (или воссозданию) социальной микроструктуры» [6. С. 15].

У Гоголя дом также прочно ассоциируется с семейным миром: создание новой семьи - это создание новой хаты, о чем задумывается Параска, примеряя очипок мачехи, т.е. роль замужней женщины. Столь же значим мотив дома в структуре других любовноматримониальных сюжетов гоголевского цикла. Строительством новой хаты завершаются сложные перипетии «Ночи перед Рождеством», когда Вакула и Оксана предстают уже мужем и женой:

Проезжал через Диканьку блаженной памяти архиерей, хвалил место, на котором стоит село, и, проезжая по улице, остановился перед новою хатою. „А чья это такая размалеванная хата?“ спросил преосвященный у стоявшей близ дверей красивой женщины с дитятей на руках. „Кузнеца Вакулы!“ сказала ему, кланяясь, Оксана, потому что это именно была она. „Славно! славная работа!“ сказал преосвященный, разглядывая двери и окна. А окна все были 
обведены кругом красною краскою; на дверях же везде были козаки на лошадях с трубками в зубах [16. С. 243].

Примечательной деталью этого описания является барочный космологический орнамент, эмблематически вмещающий в себя весь казацкий мир. Здесь новый дом, как в «Приветствие <...> Алексию Михайловичу <...> о вселении его благополучном в дом <...> в селе Коломенском новосозданный» Симеона Полоцкого, становится центром и микромоделью Вселенной («По царстей чести и дом зело честный, // несть лучше его, разве дом небесный» [23. С. 105] $]^{7}$ ). Размещен орнамент на окнах и дверях, близ которых стоит хозяйка, т.е. на казовой стороне, где происходит прием гостей, что подчеркивает не только космологичность, но и коммуникативный посыл, настроенность на особую торжественность, уподобляющую дом храму (ср. роль архиерея в эпизоде).

Прочитывая в религиозно-мистическом плане данный и подобные эпизоды, С.А. Гончаров возводит их к метасюжету цикла, построенному, по мнению исследователя, на компенсации семейной ущербности или сиротства героев, за которыми стоит гностическая проблематика плененной Софии, через «коллизии восстановления сакрального миропорядка, эквивалентом которого становится мотивика брака, нового дома и Богоматери» [9. С. 43]. К образу последней отсылает, в частности, Оксана с ребенком на руках, стоящая в «раме» дверного проема. В схожем русле интерпретирует мотивы брака-строительства М. Вайскопф: «Зияния в <...> теле мира стягиваются, восстанавливая единство земного дома - “новой хаты” из CЯ» [10. C. 155].

Подобные смысловые планы не отменяют в то же время роли ритуальной семантики дома. В ее пределах у двери и окна был ряд специфических функций. В первую очередь они определялись ролью в моделировании природно-космологической сферы и отграничения от нее человеческого пространства. Так, в восточнославянском жилище строго регламентировалось расположение окон и дверей в соответствии со сторонами света. Изначально «вход, служивший одновременно источником дневного света, ориентировался преимущественно на юго-восточные румбы» [6. С. 81], однако с разделением функций двери и окна их расположение дифференцировалось: в северновеликорусском, украинском и белорусском плане жилища

\footnotetext{
${ }^{7}$ Подробнее о барочной эмблематике дома см. в нашей статье: [24. С. 5-11].
} 
в эту сторону смотрят окна, а дверь обращена на северо-запад [25. C. 234]. Подобная структурированность вносила в семантику окна отсылки к солнцу, теплу, космическому «верху», здесь располагался красный угол и совершались молитвы ; дверь, близ которой помещалась печь, была выходом в сферу «холода» и хтонических природных стихий, через нее осуществлялись коммуникация с людьми и взаимодействие с миром мертвых. Космологическая привязка определяла и ряд пространственных оппозиций, спроецированных уже на социальную структурированность дома: центр - периферия, правая половина - левая половина, внутренняя сфера - внешняя сфера. Первые части оппозиций связывались тем самым с юго-востоком и с оконной стороной (красный угол, место хозяина, мужская половина), вторая, соответственно, с дверью и северо-западом (хозяйственная часть, бабий угол).

Гоголь сохранил в повестях многие гендерно-поколенческие приметы в структуре восточнославянского жилища, связанные с местом женских и мужских персонажей, отцов и детей. При всей карнавальной путанице отношения между членами семьи здесь в целом иерархичны и традиционны, что воплощается и в распределении домашнего пространства. В «Вечерах» мы периодически переносимся то в женскую, преимущественно девичью, половину хаты, то в мужскую, свою роль играют и печь, и красный угол, разделены зоны старшего и младшего поколения. В «Сорочинской ярмарке» и «Ночи перед Рождеством» наиболее подробны и колоритны образы женского мира дома, в «Страшной мести» и «Иване Федоровиче Шпоньке и его тетушке» основное внимание уделено миру мужскому'

При описании женской половины в повествовании нередко возникает мотив заглядывания и подглядывания, которые совершают не только герои, но и сам рассказчик, виртуально проникающий в более закрытую, в сравнении с мужской, домашнюю сферу, хотя в пространственном плане именно она расположена ближе к выходу, к двери, где находятся печь, посуда и хозяйственная утварь, где происходит готовка и куда сначала попадает гость. Подобная локализация облегчает неожиданное проникновение. Так, у входа нечаянно застает Черевик танцующую Параску: «Черевик заглянул в это время в дверь и, увидя дочь свою танцующею перед зеркалом, остано-

\footnotetext{
${ }^{8}$ О связи молитвенных ритуалов и семантики окна см. [26. С. 114-125].

${ }^{9}$ См. опыт интерпретации роли гендерного компонента в «Вечерах» [27. С. 262-267].
} 
вился» [16. С. 134]. В следующий момент, узнав о сватовстве, девушка бросается к двери: «Не успела переступить она за порог хаты, как почувствовала себя на руках парубка в белой свитке» [16. C. 135]. Почти так же застает Оксану сначала повествователь («Теперь посмотрим, что делает, оставшись одна, красавица дочка» [16. C. 206]), а затем и Вакула: «Чудная девка! - прошептал вошедший тихо кузнец, - и хвастовства у нее мало! С час стоит, глядясь в зеркало, и не наглядится, и еще хвалит себя вслух!» [16. С. 207].

В сюжетах гоголевских повестей, построенных на любовноавантюрной коллизии, бытовая жизнь женской половины, проходящая сугубо внутри дома, отодвинута в тень, и женщины предстают в коммуникативных ситуациях, в моментах контакта с внешним миром, чаще всего генетически связанных с ритуалами сватовства. В них значим акт пересечения границы - двери и порога ${ }^{10}$, особенно если он происходит неожиданно. Олеся сурово упрекает кузнеца за такое нарушение ритуала: «Зачем ты пришел сюда? - так начала говорить Оксана. - Разве хочется, чтобы выгнала за дверь лопатою? Вы все мастера подъезжать к нам. Вмиг пронюхаете, когда отцов нет дома» [16. С. 208]. Напротив, традиционная форма ухаживания, подразумевающая выполнение фольклорно одобренных обрядов - песни под окном, способствует добровольному пересечению границы и счастливому свиданию, как у Ганны и Левко, пусть и не одобряемому старшими:

«Нет, видно, крепко заснула моя ясноокая красавица! - сказал козак, окончивши песню и приближаясь к окну. <...> Просунь сквозь окошечко хоть белую ручку свою...» <...> Деревянная ручка у двери в это время завертелась: дверь распахнулась со скрыпом, и девушка на поре семнадцатой весны, обвитая сумерками, робко оглядываясь и не выпуская деревянной ручки, переступила через порог [16. С. 154].

Характерно, что в сценах адюльтера, очевидного отступления от патриархальной нормы, Гоголь не упоминает окна как канала коммуникации, а дверь становится для гостя источником потенциальной угрозы - внезапного стука вернувшегося хозяина. Хавронья или Солоха приводят своих любовников через ход, не предназначенный для ритуально одобренного проникновения: первая - через плетень

${ }^{10}$ О лиминальных мотивах в обряде сватовства и свадьбы см. в книге А.К. Байбурина: [28. С. 62-89] (раздел «Не состоящий в браке - состоящий в браке»). 
(«Сюда, Афанасий Иванович! Вот тут плетень пониже, поднимайте ногу, да не бойтесь...» [16. С. 122], а вторая, будучи ведьмой, - через печную трубу, орудие связи с огненным миром преисподней [29. С. 101-109]: («...спустилась по воздуху, будто по ледяной покатой горе, и прямо в трубу. Черт таким же порядком отправился вслед за нею» [16. С. 210]).

Роль двери и окна как пороговых зон актуальна в еще одном значимом контексте, связанном со свадебной обрядовостью. В славянском фольклоре свадьба, являющаяся ритуалом инициации, перекликается с похоронами и включает в себя образы смерти, проникновения в потусторонний мир, контакт с предками [30. С. 188-196]. Причем, как констатируют А.К. Байбурин и Г.А. Левинсон, в женской части свадебного обряда мотивов смерти гораздо больше: для жениха временное инициационное умирание лишь обозначается, для невесты предстает важной фазой (ритуальное омовение, одевание, выход и другие элементы, эквивалентные похоронным) [31. С. 64-98].

Мортальные и демонологические мотивы, сопутствующие женским персонажам у Гоголя, неоднократно становились предметом внимания [32. С. 131-141; 33. С. 118-127; 34. С. 138-152; 35. С. 147173], поэтому акцентируем лишь их связь с пространственной лиминальностью, последовательно проявленной в «Вечере накануне Ивана Купалы». Все свидания Петра и Пидорки происходят в переходных зонах - либо на мосту, либо в сенях, где однажды в темноте жених влепляет поцелуй вместо невесты ее отцу Коржу: «...лукавый <...> настроил сдуру старого хрена отворить дверь хаты. Одеревянел Корж, разинув рот и ухватясь рукою за двери» [16. С. 142]. Здесь сени предстают обманчивым пространством, где властен лукавый, подстрекающий героев к опрометчивым поступкам. В следующем эпизоде уже сам дом для девушки выступает символическим гробом, а немилая свадьба с ляхом мыслится как похороны:

И родной отец - враг мне: неволит итти за нелюбого ляха. Скажи ему, что и свадьбу готовят, только не будет музыки на нашей свадьбе; будут дьяки петь, вместо кобз и сопилок. Не пойду я танцовать с женихом своим; понесут меня. Темная, темная моя будет хата: из кленового дерева, и, вместо трубы, крест будет стоять на крыше! [16. С. 142].

Этой «свадьбы», которую готов разделить с невестой и Петр, однако, не происходит, но ее аналогом становится реальная свадьба, 
где обручается с Пидоркой герой, совершивший преступление и вступивший в сговор с дьяволом: «...да и заварили свадьбу: напекли шишек, нашили рушников и хусток, выкатили бочку горелки; посадили за стол молодых; разрезали коровай; брякнули в бандуры, цимбалы, сопилки, кобзы - и пошла потеха...» [16. С. 147]. Со впавшим в умопомешательство мужем Пидорка уже на деле оказывается запертой в доме-гробе: «Страшно ей было оставаться сперва одной в хате; да после свыклась бедняжка с своим горем» [16. С. 149]. В итоге тем не менее окончательно переходит рубеж миров Петрусь, а Пидорка остается по сю сторону запертой двери:

В испуге выбежала она в сени; но, опомнившись немного, хотела было помочь ему; напрасно! дверь захлопнулась за нею так крепко, что не под силу было отпереть. Сбежались люди; принялись стучать; высадили дверь: хоть бы душа одна [16. С. 150].

Подобная связь лиминальных элементов дома с обрядовыми мотивами свадьбы / похорон присутствует в «Майской ночи», где дополнительно возникает образный комплекс венчания неженатой умершей, бытующий в славянском и в том числе украинском фольклоре [36. С. 225-228], в «Страшной мести», где инцестуальным женихом Катерины становится отец-колдун, в «Иване Федоровиче Шпоньке и его тетушке», где она предстает в травестированном виде незадачливого сватовства.

При всей мотивной сложности в «Вечерах» инстанцией, определяющей законность или незаконность присутствия гостя и возможность его контактов с женской половиной, особенно в форме сватовства, выступает неизменно хозяин-мужчина, своеобразный хранитель границы. Это тоже вносит в образы отцов или мужей элемент демонологической семантики, объясняющей их суровость, запреты, в определенные моменты иррациональность мотиваций. Акцентируя ее в русле гностической интерпретации, С.А. Гончаров утверждает: «ОТЦЫ, в свою очередь, также соотнесены, прямо или косвенно, с инфернальной сферой и “чужим” миром: в “Страшной мести” отец Катерины - колдун и Антихрист <...> в других повестях они отмечены либо подчиненностью мачехе-ведьме (т.е. выступают пассивными орудиями злой силы), либо наделены признаками, которые в фольклорно-мифологической системе имеют инфернальную семантизацию (одноглазость и пр.)» [9. С. 38-39]. 
Можно заметить вместе с тем, что у Гоголя «демонизированная» функция источника запретов и хранителя границы-двери нередко травестируется и становится источником ряда карнавальных положений. Так, Чуб, заплутавший по дороге, принимает за хозяина своего дома Вакулу, который сам здесь находится на положении гостя, но, примеряя роль мужа Оксаны, намеревается «отломать с досады бока» [16. С. 210] незваному посетителю:

Хлопая намерзнувшими на холоде руками, принялся он (Чуб) стучать в дверь и кричать повелительно своей дочери отпереть ее.

„Чего тебе тут нужно?““ сурово закричал вышедший кузнец.

Чуб, узнавши голос кузнеца, отступил несколько назад. „Э, нет, это не моя хата“, говорил он про себя: „в мою хату не забредет кузнец. <...> Чья бы была это хата? Вот на! не распознал! это хромого Левченка, который недавно женился на молодой жене. <...> Однако ж Левченко сидит теперь у дьяка, это я знаю, зачем же кузнец?.. Э, ге, ге! он ходит к его молодой жене. Вот как! хорошо!.. теперь я все понял“ [16. С. 213].

Завязавшаяся перепалка «хозяина» и «гостя» является немногочисленным примером нарушения обрядовых норм пересечения границы, что Чуб пытается оправдать карнавальной вольностью колядования («...чего доброго, еще приколотит проклятый выродок!“ и, переменив голос, отвечал: „Это я, человек добрый! пришел вам на забаву поколядовать немного под окнами“» [16. С. 213]. Еще один подобный пример мы найдем в «Вечере накануне Ивана Купалы», где незадачливого Петруся после «поцелуя» выпроваживает с тумаками Корж, запретив даже приближаться к лиминальным зонам двери и окну: «вывел он его потихоньку из хаты: „Если ты мне когда-нибудь покажешься в хате, или хоть только под окнами, то слушай, Петро: ей богу, пропадут черные усы, да и оселедец твой $\langle\ldots\rangle$ “» [16. С. 142].

Инициаторами приема гостей или гостями тем самым являются в первую очередь мужчины, как Черевик, идущий с ярмарки «с кумом и дочкою, которые вместе с напросившимися к ним в хату гостьми произвели сильный стук, так перепугавший нашу Хиврю. <...> Гости тоже были в веселом расположении духа и без церемонии вошли прежде самого хозяина» [16. С. 124]. Это определяется публичностью их положения в родовом сообществе, где именно они осуществляют санкционированную коммуникацию (общение женщин неофициально и принимает форму слухов и пересудов, чаще всего 
недостоверных, как в «Ночи перед Рождеством»). Тот же Черевик мыслит выход из дома и посещение новой хаты дьяка не только поводом для попойки, но и выполнением этикетного долга поздравить с новосельем, и желанием поговорить с уважаемыми (голова), новыми (бас) или интересными (дегтярь Микита) людьми:

„Так ты, кум, еще не был у дьяка в новой хате?“ - говорил козак Чуб, выходя из дверей своей избы <...>. Ему до смерти хотелось покалякать о всяком вздоре у дьяка, где, без всякого сомнения, сидел уже и голова, и приезжий бас, и дегтярь Микита, ездивший через каждые две недели в Полтаву на торги и отпускавший такие шутки, что все миряне брались за животы со смеху [16. С. 205].

При всей важности границ свободное общение жителей одного селения - отличительная черта в мире «Вечеров». Как справедливо констатировал В.А. Кошелев, «“гостеванье” становится организующим сюжетным мотивом первого цикла гоголевских повестей: основные события происходят именно “в гостях” [37. С. 99], что воплощает карнавальную свободу общения, публичность родового быта и прочность социальных связей - в отличие от более позднего «Миргорода». С приглашения в гости начинает свой рассказ и сам Рудый Панько, для которого это и патриархальный этикет, и требование души, подразумевающее обильное, до отвала угощение, приобщение к миру хозяина: «Приезжайте только, приезжайте поскорей; а накормим так, что будете рассказывать и встречному и поперечному» [16. С. 124]. Обязательное угощение здесь - ритуальное действо, сопровождаемое беседой, т.е., по сути, акт не только бытовой, но и коммуникативно-информационный, следствием же гостеванья и угощенья является добрая слава о хозяине, распространяющаяся как в ближней родовой сфере, так и, по замыслу Панька, в космологических масштабах - до «инобытийного» Петербурга.

«Гостеванье» требует особого внимания к акту пересечения границы - порога хозяйского жилища, сфере детально регламентированной в восточнославянских обрядах. Знаковым становится открывание двери при входе и выходе как для хозяев, так и для гостей, оно сопровождается «микрообрядом» встречи / прощания, дорожной молитвы («Без Бога - ни до порога») и провожания ${ }^{11}$. В «Ночи перед Рождеством» характерен следующий эпизод: «Пацюк, верно, крепко

11 «Гостя встречай за порогом и пуская наперед себя через порог. Через порог не здороваются. Через порог руки не подают» [38. С. 319]. 
занят был галушками, потому что, казалось, совсем не заметил прихода кузнеца, который, едва ступивши на порог, отвесил ему пренизкий поклон» [16. С. 223]. Здесь порог выступает в двойной роли: с одной стороны, как место бытовых ритуалов приветствия, соблюдение или нарушение которых определяет возможность коммуникации между гостем и хозяином, а с другой - обозначает космологическую границу, зону «иного» пространства, откуда приходит гость ${ }^{12}$, хотя в данном случае демонологическим персонажем является Пацюк.

Целый ряд обрядовых примет в контексте демонологических мотивов вспоминает, в частности, винокур в «Майской ночи», когда в дом головы нежданно вторгается пьяный Каленик. Изначально собрание проходит в полном соответствии с ритуалом, включая рассаживание гостей: «Под самым покутом ${ }^{13}$, на почетном месте, сидел гость (винокур)» [16. С. 164]; «На конще стола курил люльку один из сельских десятских, составлявших команду головы, сидевший из почтения к хозяину в свитке» [16. С. 165]. Однако потом происходит вопиющее нарушение, что акцентируется неблагообразием пересечения многократно упоминаемого порога:

В это время что-то стало шарить за дверью; дверь растворилась, и мужик, не снимая шапки, ступил за порог и стал, как будто в раздумьи, посреди хаты, разинувши рот и оглядывая потолок. Это был знакомец наш, Каленик. „Вот, я и домой пришел!““ говорил он, садясь на лавку у дверей ${ }^{14}$ и не обращая никакого внимания на присутствующих [16. С. 166].

Реакцией на подобное своеволие, как и в ряде приведенных выше эпизодов, становится хозяйский запрет, отказ в приеме гостя: «,За это люблю“, сказал голова: „пришел в чужую хату и распоряжается, как дома! Выпроводить его по добру по здорову!..“» [16. C. 166]. Но карнавальный контекст сцены и опьянение Каленика заставляют собравшихся отнестись к нему как своего рода юродивому: «Винокур верил всем приметам, и тотчас прогнать человека, уже севшего на лавку, значило у него накликать беду» [16. С. 166]. И далее винокур, блюститель ритуалов, советует даже не бранить

\footnotetext{
${ }^{12}$ О семантике «чуждости» в образе гостя см.: [39. С. 442-445].

${ }^{13}$ Место под образами, красный угол.

${ }^{14}$ Так называемая «нищая лавка», куда мог сесть без разрешения хозяина гость «Христа ради».
} 
виноватого («Боже сохрани тебя, и на том, и на этом свете, поблагословить кого-нибудь такою побранкою!» [16. С. 167], а в подкрепление своих слов рассказывает притчу-быличку о своей теще, пожалевшей галушку голодному прохожему:

Вдруг откуда ни возьмись человек, какого он роду, бог его знает, просит и его допустить к трапезе. Как не накормить голодного человека! Дали и ему спичку. Только гость упрятывает галушки, как корова сено. 〈..> „А чтоб ты подавился этими галушками!“ - подумала голодная теща; как вдруг тот поперхнулся и упал. Кинулись к нему - и дух вон. Удавился. <...> с того времени покою не было теще. Чуть только ночь, мертвец и тащится. Сядет верхом на трубу, проклятый, и галушку держит в зубах [16. С. 167].

С ролью дома как центра обрядности связана также информационно-регламентирующая функция. Именно в доме человек получает важнейшие сведения о природно-космической и социальной организации действительности. Он «считывает» их визуально из символических кодов, определяющих видимую организацию домашнего пространства, а также из обрядов, как театрализованных действ. Еще одним каналом является практическая деятельность, хозяйственные навыки, приобретаемые в работе по дому. Наконец, дом - это еще и сфера концентрации вербальных текстов, связанных с обрядами, фольклором и трудом. «Вербальным путем передавалась своеобразная “домашняя" мифология. Существенная часть обязательного корпуса текстов усваивалась и воспроизводилась исключительно во время так называемых “домашних” работ» [6. С. 13]. Последний аспект, воспроизведение и восприятие во время домашних трудов и отдохновений текстов разного плана, окажется очень важен уже для литературной традиции, обретя вид особого жанра «вечеров», где герои, собравшиеся в некоем доме, рассказывают друг другу истории. От писателей Возрождения (Дж. Боккаччо, М. Наваррская) эта нарративная форма перейдет к романтикам, у которых станет органичным воплощением универсального мировоззрения и инструментом циклизации текстов (Э.Т.А. Гофман, Н.В. Гоголь) [40. С. 6381; 41. C. 15-25].

Совместное домашнее собрание и рассказывание историй в «Вечерах», будучи вынесенным в заглавие, определило саму жанровую форму и принцип циклизации, восходящий к устно-обрядовой коммуникации с ее привязанностью текста к ритуальной ситуации об- 
щения. У Гоголя ею явилось рекреационное игровое действо, близко связанное со свадебно-любовной сферой (пространство встреч девушек и парней и тем самым поиска жениха / невесты ${ }^{15}$ ):

...только вечер, уже наверно где-нибудь в конце улицы брежжет огонек, смех и песни слышатся издалеча, бренчит балалайка, а подчас и скрыпка, говор, шум... Это у нас вечерницыь! <...> соберется в одну хату толпа девушек совсем не для балу, с веретеном, с гребнями; и сначала будто и делом займутся: веретена шумят, льются песни, и каждая не подымет и глаз в сторону; но только нагрянут в хату парубки с скрыпачом - подымется крик, затеется шаль, пойдут танцы и заведутся такие штуки, что и рассказать нельзя. Но лучше всего, когда собьются все в тесную кучку и пустятся загадывать загадки или просто нести болтовню. Боже ты мой! Чего только ни расскажут! Откуда старины ни выкопают! Каких страхов ни нанесут! [16. С. 104].

На подобных вечерницах происходит санкционированное обычаем пересечение границ жилища большим собранием молодых гостей, поводом для которого является совместная работа, оборачивающаяся весельем, играми и ухаживаниями. Разделение на женскую и мужскую часть здесь отменяется, дверь дома открыта для всех, а информационное пространство распахивается в хронологическом и космологическом плане.

Последний аспект отражает функциональную связь в восточнославянской семантике жилища брачного и воспитательного комплексов: вечерницы только с одной стороны - пространство свадебно-любовных игр, которые должны закончиться созданием нового дома, а с другой - повод для передачи значимой информации, родовой памяти, облеченной в том числе в нарративные формы быличек и легенд. Они для собравшихся становятся сводом мифологических прецедентов из «старины», призванным предотвратить «неправильное» поведение и утвердить его этически-ритуальную норму. Как констатирует Л.Н. Виноградова, «былички, тематически связанные с нарушением принятых в социуме обычаев, могут рассматриваться как тексты сюжетно оформленных иллюстраций, наглядных пособий, примеров из жизни, предназначенных для обучения правилам коммуникации с потусторонним миром» [43. С. 215]. Подобное «воспитательное» задание в гоголевских повестях присутствует

\footnotetext{
${ }^{15}$ О матримониальных функциях «вечерниц» и их аналогов см.: [42. С. 196-200].
} 
обычно лишь на уровне фона, однако в «Вечере накануне Ивана Купала» и «Страшной мести» акцентируется, в том числе через композицию (история - и ее сакральный объясняющий претекст), а в «Сорочинской ярмарке» имеет сюжетную роль: быличка о красной свитке помогает разрешить любовную коллизию.

Из лиминальных элементов домашнего пространства в эпизодах собраний с рассказыванием историй или пением песен (сцены колядования в «Ночи перед Рождеством», гуляний и проделок молодежи в «Майской ночи», ярмарки в «Сорочинской ярмарке») чаще всего упоминается окно. А.К. Байбурин в статье «Окно в звуковом пространстве» описал особый пласт смыслов, связанных с ритуальнообрядовым прислушиванием и подслушиванием у окна, реализующим желание узнать что-либо во внешнем мире (хозяева) или о происходящем в жилище (гости) [44. С. 120-133]. Подобная звуковая семантика оказывается важной в гаданиях, колядовании, приметах о том или ином звуке (особенно стуке в окно). У Гоголя подобные мотивы актуализируются, как правило, в камерных сценах, например любовной «серенады» и последующего свидания Левко и Ганны (см. выше), и реализуются в ситуации «девы у окна».

В коллективных же эпизодах доминирует скорее карнавальная логика, когда окно, не предназначенное для проникновения, а только для коммуникации, становится заместителем двери: в его раме внезапно материализуется и пересекает границу дома то, что еще недавно представало в форме образа, было предметом рассказа / песни. Слово или звук онтологизируются и приобретают самостоятельную сущность, как в финале рассказа о красной свитке: «Другая половина слова замерла на устах рассказчика. Окно брякнуло с шумом; стекла, звеня, вылетели вон, и страшная свиная рожа выставилась, поводя очами, как будто спрашивая: а что вы тут делаете, добрые люди?» [16. С. 127]. Еще один подобный эпизод завершает бурные гуляния парубков и девчат в «Майской ночи», когда голова и его гости вначале прислушиваются к несущейся из-за окна песне («Тут голова остановился. Под окном послышался шум и топанье танцующих. Сперва тихо звукнули струны бандуры, к ним присоединился голос. Струны загремели сильнее; несколько голосов стали подтягивать, и песня зашумела вихрем» [16. С. 168], а затем их вводит в ужас таинственная подмена свояченицы через то же окно: «Голова стал бледен, как полотно; винокур почувствовал холод, и волосы его, казалось, хотели улететь на небо; ужас изо- 
бразился в лице писаря; десятские приросли к земле и не в состоянии были сомкнуть дружно разинувших ртов своих: перед ними стояла свояченица» [16. С. 172].

Во второй части «Вечеров» окно уже потеряет связь с карнавалом и станет в «Страшной мести» каналом проникновения подлинно демонических сил, а в «Иване Федоровиче Шпоньке и его тетушке» прервется и прямая связь с народной ритуально-обрядовой средой, переставшей нормировать картину мира и правила коммуникации. Тем самым «воспитательная» установка былички и ее карнавального аналога анекдота, важнейших жанровых форм во всем творчестве Гоголя, будучи перенесена из соборного мира вечерниц в расщепленную сферу современного быта и нагружена пластической «материализующей» выразительностью, заставит автора во все более рельефных обликах изображать негативное начало в человеке и обществе, но сделает невозможным столь же полное воссоздание нормы, органично соединяющей все начала мироздания. Уже в «Миргороде» дом перестанет быть подлинным центром космоса, соединением его вертикали и горизонтали, что глубоко изменит и семантику лиминальных элементов - окна и двери.

\section{Лumepamypa}

1. Карпенко А.И. Народные истоки эпического стиля исторических повестей Н.В. Гоголя. Черновцы, 1961.

2. Еремина В.И. Н.В. Гоголь // Русская литература и фольклор (1-я пол. 19 в.). Л., 1976.

3. Зареикий В.А. Народные исторические предания в творчестве Н.В. Гоголя: История и биографии. Стерлитамак; Екатеринбург, 1999.

4. Гольденберг А.X. Фольклорные и литературные архетипы в поэтике Н.В. Гоголя: дис. ... д-ра филол. наук. Волгоград, 2007.

5. Гоголь Н.В. Полное собрание сочинений: в 14 т. М.; Л.: Изд-во АН СССР, 1952. T. 9.

6. Байбурин А.К. Жилище в обрядах и представлениях восточных славян. Л.: Наука, 1983.

7. Смирнов И.П. Формирование и трансформация смысла в ранних текстах Гоголя («Вечера на хуторе близ Диканьки») // Rassian Literature. 1979. Vol. 7. С. 585-600.

8. Манн Ю.В. Динамика русского романтизма. М.: Аспект Пресс, 1995.

9. Гончаров С.А. Творчество Гоголя в религиозно-мистическом контексте. СПб.: Изд-во РГПУ им. А.И. Герцена, 1997.

10. Вайскопф M. Сюжет Гоголя: Морфология. Идеология. Контекст. М.: РГГУ, 2002.

11. Дмитриева Е.E. Н.В. Гоголь в западноевропейском контексте: между языками и культурами. М.: ИМЛИ РАН, 2011. 
12. Сазонова Л.И. Память культуры. Наследие Средневековья и барокко в русской литературе Нового времени. М.: Рукописные памятники Древней Руси, 2012.

13. Фиалкова Л.Л. К проблеме «Гоголь и фольклор» // Фольклорная традиция в русской литературе. Волгоград, 1986.

14. Софронова Л.А. Мифопоэтика раннего Гоголя. СПб.: Алетейя, 2010.

15. Киселев В.С. К проблеме дискурсивных практик русской прозы первой трети XIX века (стратегия дилетантизма) // Филол. науки. 2005. № 1. С. 13-24.

16. Гоголь Н.В. Полное собрание сочинений: в 14 т. М.; Л.: Изд-о АН СССР, 1940. T. 1.

17. Березович Е.Л. Язык и традиционная культура: Этнолингвистические исследования. М.: Индрик, 2007.

18. Лотман Ю.М. Художественное пространство в прозе Гоголя // Лотман Ю.М. О русской литературе. СПб., 2005.

19. Топоров В.Н. К символике окна в мифопоэтической традиции // Балтославянские исследования. 1983. М., 1984.

20. Wilgus D.K. The girl in the window // Western Folklore. 1970. Vol. 29, № 4. P. 251-256.

21. Болотникова О.Н. «Дева у окна» и «стук у врат»: семантика мотивов окна и двери в русской литературе 1810-1830-х годов // Вестн. Том. гос. ун-та. 2016. № 405 .

22. Крейцер А.В. О природе зеркальных изображений в творчестве раннего Гоголя // Литература и фольклор: Проблемы взаимодействия. Волгоград, 1992.

23. Полочкий Симеон. Избранные сочинения. Л.: Изд-во АН СССР, 1953. C. 105.

24. Болотникова О.Н. Дверь и окно в контексте барочной эмблематики дома // Вестн. Том. гос. ун-та. 2015. № 397. С. 5-11.

25. Бломквист Е.Э. Крестьянские постройки русских, украинцев и белорусов // Восточнославянский этнографический сборник. М., 1956.

26. Мороз А.Б. Божница и окно: семиотические параллели // Слово и культура. M., 1998. T. 2.

27. Синцова C.B. Гендерная проблематика «Вечеров на хуторе близ Диканьки» как результат взаимодействия фольклорных и литературных традиций // Филология и культура. 2011. № 23. С. 262-267.

28. Байбурин А.К. Ритуал в традиционной культуре: Структурно-семантический анализ восточнославянских обрядов. СПб.: Наука, 1993.

29. Невская Л.Г. Печь в фольклорной модели мира // Исследования в области балто-славянской духовной культуры: Загадка как текст. Вып. 2. М.: Индрик, 1999.

30. Соколова В.K. Об историко-этнографическом значении народной поэтической образности (образ свадьбы-смерти в славянском фольклоре) // Фольклор и этнография. Связи фольклора с древними представлениями и обрядами. Л., 1977.

31. Байбурин А.К., Левинтон Г.А. Похороны и свадьба // Исследования в области балто-славянской духовной культуры: Погребальный обряд. М., 1990.

32. Кривонос В.Ш. «Женщина влюблена в чорта»: («Дамская» тема в «Петербургских повестях» Гоголя) // Кормановские чтения. Ижевск, 1998. Вып. 3.

33. Звездин A. Образ ведьмы у Гоголя: фольклорные истоки и средневековая мистика (попытка реконструкции интертекста) // Гоголь как явление мировой литературы. М., 2003. 
34. Дмитриева E.E. «Пожив в такой тесной связи с ведьмами и колдунами...»: (Об особенностях гоголевского фольклоризма: «Вечера на хуторе близ Диканьки») // Н.В. Гоголь и мировая культура. Вторые гоголевские чтения. М., 2003.

35. Бочаров С.Г. «Красавица мира». Женская красота у Гоголя // Бочаров С.Г. Филологические сюжеты. М., 2007.

36. Виноградова Л.Н. Похороны-свадьба // Славянские древности. М., 2009. T. 4.

37. Кошелев В.А. «Э, нет, это не моя хата...»: (Мотив «хозяева и гости» в произведениях Гоголя) // Феномен Гоголя. СПб., 2011.

38. Даль В.И. Толковый словарь живого великорусского языка. М.: Госиздат, 1955. T. 3 .

39. Невская Л.Г. Концепт «гость» в контексте переходных обрядов // Из работ московского семиотического круга. М.:, 1997.

40. Янушкевич А.С. Три эпохи литературной циклизации: Боккаччо - Гофман Гоголь (статья первая) // Вестн. Том. гос. ун-та. Филология. 2008. № 2. С. 63-81.

41. Киселев В.С. «Арабески» Н.В. Гоголя и традиции романтической циклизации // Изв. Рос. акад. наук. Сер. лит. и яз. 2004. Т. 63, № 6. С. 15-25.

42. Узенева Е.С. Посиделки // Славянские древности. М., 2009. Т. 4.

43. Виноградова Л.Н. Социорегулятивная функция суеверных рассказов о нарушителях запретов и обычаев // Славянский и балканский фольклор: Семантика и прагматика текста. М., 2006.

44. Байбурин А.К. Окно в звуковом пространстве // Евразийское пространство: Звук, слово, образ. М., 2003.

\section{HOUSE, DOOR AND WINDOW IN GOGOL'S EVENINGS ON A FARM NEAR DIKANKA AND SEMIOTICS OF THE EASTERN SLAVIC HOUSE}

Bolotnikova Olesya N. Tomsk State University (Tomsk, Russian Federation). E-mail: bolotnikova@mail.ru.

Imagology and Comparative Studies, 2016, 1(5), pp. 153-176. DOI:10.17223/24099554/5/9

Keywords: mythopoetics, Semiotics of Eastern Slavic house, N.V. Gogol, Evenings on a Farm near Dikanka, house space, door, window.

The article discusses Gogol's mythopoetics of the house considered in the context of the Eastern Slavic ritual culture. Evenings on a Farm near Dikanka reflects the cosmogony, social and communicative aspects of meanings related to the structuring of the house space. Gogol emphasizes the special role of the house already on the description level, which, being quite detailed, is saturated with socio-characterological and / or cosmological meanings: it helps to introduce the reader into the world of the character, and to locate the character in the universal mythological space. In cosmological terms, the house in Evenings on a Farm near Dikanka is an intersection point of the vertical, linking heaven and hell, and horizontal, social and routine, organization of space.

From a social point of view, the house is, above all, the kin, the family. Gogol's house is strongly associated with the world of the family: the creation of a new family is the construction of a new house. In his story, the writer preserved many gender-generational signs in the structure of East Slavic dwellings based on the location of male and female characters, parents and children. In the plots of Gogol's stories built on love-adventurous conflicts, domestic life of the female half, going exclusively inside the house, is moved to the 
background, and women appear in communicative situations, in moments of contact with the outside world, that are often genetically related to the rituals of courtship. In these rituals, a significant act is crossing the border - the door and the threshold. In Slavic folklore, the wedding, a ritual of initiation, overlaps with the funeral and includes images of death, penetration in the other world, contact with the ancestors.

In Evenings, the instance that determines the legality or illegality of the guest's presence and the possibility of his contact with the female half, especially in the form of courtship, is always the owner, a man, a kind of a guardian of the border. This is determined by the publicity of their position in the family community where they are the ones to carry out authorized communication. Free communication of inhabitants of one village is a distinctive feature in the world of Evenings, which reflects the collective nature of family life and strength of social ties. "Visitality" requires special attention to the act of crossing the border - the threshold of the owner's home, the area thoroughly regulated in the East Slavic rites. The opening of the door at the entrance and exit for the hosts and guests is significant, it is accompanied by a "micro-rite" of the meeting, farewell and seeing off.

The role of the house as a center of ritual also includes the information and regulatory function. Joint meeting at home and storytelling in Evenings, as in the title, determined the genre itself and the cyclization principle. Evenings, on the one hand, are the space of wedding and love games that should result in the construction of a new house; on the other hand, they are a reason for transmitting important information, ancestral memory, sometimes in the narrative form of true stories and legends. For the gathered people they are mythological precedents of the "old time" set to prevent "abnormal" behavior, and to establish its ethical and ritual norm.

\section{References}

1. Karpenko, A.I. (1961) Narodnye istoki epicheskogo stilya istoricheskikh povestey N.V. Gogolya [Folk origins of the epic style of the historical stories of Nikolai Gogol]. Chernovtsy.

2. Eremina, V.I. (1976) N.V. Gogol' [N.V. Gogol]. In: Russkaya literatura i fol'klor (1-ya pol. 19 v.) [Russian Literature and Folklore (1st half of the 19th c.)]. Leningrad: Nauka.

3. Zaretskiy, V.A. (1999) Narodnye istoricheskie predaniya $v$ tvorchestve N.V. Gogolya: Istoriya i biografii [Folk historical tradition in the works of N.V. Gogol: History and biography]. Sterlitamak; Ekaterinburg.

4. Gol'denberg, A.Kh. (2007) Fol'klornye $i$ literaturnye arkhetipy $v$ poetike N.V. Gogolya [Folklore and literary archetypes in the N.V. Gogol's poetics]. Philology Dr. Diss. Volgograd.

5. Gogol, N.V. (1952) Polnoe sobranie sochineniy: v 14 t. [Complete Works: in 14 vols]. Vol. 9. Moscow; Leningrad: USSR AS.

6. Bayburin, A.K. (1983) Zhilishche $v$ obryadakh i predstavleniyakh vostoch-nykh slavyan [Dwelling in the rites and beliefs of the Eastern Slavs]. Leningrad: Nauka.

7. Smirnov, I.P. (1979) Formirovanie i transformatsiya smysla v rannikh tekstakh Gogolya ("Vechera na khutore bliz Dikan'ki") [Formation and transformation of sense in the early texts of Gogol (Evenings on a Farm near Dikanka)]. Russian Literature. VII. pp. 585-600.

8. Mann, Yu.V. (1995) Dinamika russkogo romantizma [Dynamics of Russian romanticism]. Moscow: Aspekt Press. 
9. Goncharov, S.A. (1997) Tvorchestvo Gogolya v religiozno-misticheskom kontekste [Gogol's work in the religious and mystical context]. St. Petersburg: Herzen State Pedagogical University of Russia.

10. Weisskopf, M. (2002) Syuzhet Gogolya: Morfologiya. Ideologiya. Kontekst [Gogol's plot: Morphology. Ideology. Context]. Moscow: RSUH.

11. Dmitrieva, E.E. (2011) N.V. Gogol'v zapadnoevropeyskom kontekste: mezhdu yazykami i kul'turami [N.V. Gogol in the Western European context, between languages and cultures]. Moscow: Institute of World Literature RAS.

12. Sazonova, L.I. (2012) Pamyat' kul'tury. Nasledie Srednevekov'ya i barokko v russkoy literature Novogo vremeni [Memory of culture. The legacy of the Middle Ages and the Baroque in Russian literature of modern times]. Moscow: Rukopisnye pamyatniki Drevney Rusi.

13. Fialkova, L.L. (1986) K probleme "Gogol' i fol'klor" [On the problem of Gogol and folklore]. In: Medrish, D.N. (ed.) Fol'klornaya traditsiya v russkoy literature [Folk tradition in Russian literature]. Volgograd: Volgograd State Pedagogical Unniversity.

14. Sofronova, L.A. (2010) Mifopoetika rannego Gogolya [Mythopoetics of early Gogol]. St. Petersburg: Aleteyya.

15. Kiselev, V.S. (2005) K probleme diskursivnykh praktik russkoy prozy pervoy treti XIX veka (strategiya diletantizma) [On the problem of discursive practices of the Russian prose of the first third of the 19th century (dilettantism strategy)]. Filologicheskie nauki-Philological Sciences. 1. pp. 13-24.

16. Gogol, N.V. (1940) Polnoe sobranie sochineniy: $v 14$ t. [Complete Works: in 14 vols]. Vol. 1. Moscow; Leningrad: USSR AS.

17. Berezovich, E.L. (2007) Yazyk i traditsionnaya kul'tura: Etnolingvisticheskie issledovaniya [Language and traditional culture: Ethnolinguistic research]. Moscow: Indrik.

18. Lotman, Yu.M. (2005) Khudozhestvennoe prostranstvo v proze Gogolya [Art space in the prose of Gogol]. In: Lotman, Yu.M. O russkoy literature [On Russian literature]. St. Petersburg: Iskusstvo-SPB.

19. Toporov, V.N. (1984) K simvolike okna v mifopoeticheskoy traditsii [On the symbolism of the window in the mythopoetic tradition]. In: Ivanov, V.V. (ed.) Baltoslavyanskie issledovaniya. 1983 [Balto-Slavic studies. 1983]. Moscow: Nauka.

20. Wilgus, D.K. (1970) The girl in the window. Western Folklore. 29:4. pp. 251-256.

21. Bolotnikova, O.N. (2016) "Deva u okna" i "stuk u vrat": semantika motivov okna i dveri v russkoy literature 1810-1830-kh godov ["The girl in the window" and "A knock at the gate": the semantics of window and door motives in the Russian literature of the 1810-1830-ies]. Vestnik Tomskogo gosudarstvennogo universiteta - Tomsk State University Journal. (in print).

22. Kreytser, A.V. (1992) O prirode zerkal'nykh izobrazheniy v tvorchestve rannego Gogolya [On the nature of mirror images in the works of early Gogol]. In: Literatura $i$ fol'klor. Problemy vzaimodeystviya [Literature and Folklore. Problems of interaction]. Volgograd: Peremena.

23. Polotsky, S. (1953) Izbrannye sochineniya [Selected works]. Leningrad: USSR AS.

24. Bolotnikova, O.N. (2015) Door and window in the house Baroque emblems. Vestnik Tomskogo gosudarstvennogo universiteta - Tomsk State University Journal. 397. pp. 5-11. (In Russian). DOI: 10.17223/15617793/397/1

25. Blomkvist, E.E. (1956) Krest'yanskie postroyki russkikh, ukraintsev i be-lorusov [Peasant buildings of Russians, Ukrainians and Belarusians]. In: Tokarev, S.A. (ed.) 
Vostochnoslavyanskiy etnograficheskiy sbornik [East Slavic ethnographic collection]. Moscow: USSR AS.

26. Moroz, A.B. (1998) Bozhnitsa i okno: semioticheskie paralleli [Shrine and window: semiotic parallels]. In: Agapkina, T.A., Zhuravlev, A.F. \& Tolstaya, S.M. (eds) Slovo i kul'tura [Word and culture]. Vol. 2. Moscow: Indrik.

27. Sintsova, S.V. (2011) Gendernaya problematika "Vecherov na khutore bliz Dikan'ki" kak rezul'tat vzaimodeystviya fol'klornykh i literaturnykh traditsiy [Gender issues in Evenings on a Farm near Dikanka as a result of the interaction of folklore and literary traditions]. Filologiya i kul'tura - Philology and Culture. 23. pp. 262-267.

28. Bayburin, A.K. (1993) Ritual $v$ traditsionnoy kul'ture: Strukturno-semanticheskiy analiz vostochnoslavyanskikh obryadov [The ritual in the traditional culture: the structural-semantic analysis of the East Slavic rites]. St. Petersburg: Nauka.

29. Nevskaya, L.G. (1999) Pech' v fol'klornoy modeli mira [The oven in the folk world model]. In: Nikolaeva, T.M. (ed.) Issledovaniya v oblasti balto-slavyanskoy dukhovnoy kul'tury: Zagadka kak tekst [Research in Balto-Slavic spiritual culture: Riddle as text]. Vol. 2. Moscow: Indrik.

30. Sokolova, V.K. (1977) Ob istoriko-etnograficheskom znachenii narodnoy poeticheskoy obraznosti (obraz svad'by-smerti v slavyanskom fol'klore) [On the historical and ethnographic meaning of folk poetic imagery (image of wedding-death in Slavic folklore)]. In: Putilov, B.N. (ed.) Fol'klor i etnografiya. Svyazi fol'klora s drevnimi predstavleniyami i obryadami [Folklore and Ethnography. Folklore links with ancient beliefs and rituals]. Leningrad: Nauka.

31. Bayburin, A.K. \& Levinton, G.A. (1990) Pokhorony i svad'ba [The funeral and the wedding]. In: Ivanov, V.V. (ed.) Issledovaniya $v$ oblasti balto-slavyanskoy dukhovnoy kul'tury: Pogrebal'nyy obryad [Research in Balto-Slavic spiritual culture: burial rites]. Moscow: Nauka.

32. Krivonos, V.Sh. (1998) "Zhenshchina vlyublena v chorta": ("Damskaya" tema v "Peterburgskikh povestyakh" Gogolya) [A Woman in Love with the Devil ("Lady" topic in The Petersburg Stories by Gogol)]. In: Kormanovskie chteniya [Kormanovskie readings]. Vol. 3. Izhevsk: Udmurt State University.

33. Zvezdin, A. (2003) Obraz ved'my u Gogolya: fol'klornye istoki i srednevekovaya mistika (popytka rekonstruktsii interteksta) [The image of the witches of Gogol: folkloric origins and medieval mysticism (an attempt of intertext reconstruction)]. In: Vinogradov, I.A. (ed.) Gogol' kak yavlenie mirovoy literatury [Gogol as a phenomenon of world literature]. Moscow: Institute of World Literature RAS.

34. Dmitrieva, E.E. (2003) "Pozhiv v takoy tesnoy svyazi s ved'mami i koldunami..." (Ob osobennostyakh gogolevskogo fol'klorizma: "Vechera na khutore bliz Dikan'ki") ["Having lived in such a close connection with the witches and wizards..." (On features of Gogol's folklorism in Evenings on a Farm near Dikanka)]. In: Vikulova, V.P. (ed.) N.V. Gogol' i mirovaya kul'tura. Vtorye gogolevskie chteniya [N.V. Gogol and world culture. Second Gogol readings]. Moscow: KDU.

35. Bocharov, S.G. (2007) "Krasavitsa mira". Zhenskaya krasota u Gogolya ["Beauty of the world". Feminine beauty in Gogol's works]. In: Bocharov, S.G. Filologicheskie syuzhety [Philological plots]. Moscow: Yazyki slavyanskikh kul'tur.

36. Vinogradova, L.N. (2009) Pokhorony-svad'ba [The funeral-wedding]. In: Tolstoy, N.I. (ed.) Slavyanskie drevnosti [Slavic antiquities]. Vol. 4. Moscow: Mezhdunarodnye otnosheniya. 
37. Koshelev, V.A. (2011) "E, net, eto ne moya khata..." (Motiv "khozyaeva i gosti" v proizvedeniyakh Gogolya) ["Uh, no, it's not my hut..." (The motif of hosts and guests in the works of Gogol)]. In: Virolaynen, M.N. \& Karpov, A.A. (eds) Fenomen Gogolya [The phenomenon of Gogol]. St. Petersburg: Petropolis.

38. Dahl, V.I. (1955) Tolkovyy slovar' zhivogo velikorusskogo yazyka [Explanatory Dictionary of the Living Great Russian Language]. Vol. 3. Moscow: Gosizdat.

39. Nevskaya, L.G. (1997) Kontsept "gost"” v kontekste perekhodnykh obryadov [The concept "guest" in the context of transition rites]. In: Nikolaeva, T.M. Iz rabot moskovskogo semioticheskogo kruga [From the works of the Moscow semiotic circle]. Moscow: Yazyki russkoy kul'tury.

40. Yanushkevich, A.S. (2008) Tri epokhi literaturnoy tsiklizatsii: Bokkachcho Gofman - Gogol' (stat'ya pervaya) [The three literary epochs of cyclization: Boccaccio Hoffmann - Gogol (Article I)]. Vestnik Tomskogo gosudarstvennogo universiteta. Filologiya - Tomsk State University Journal of Philology. 2. pp. 63-81.

41. Kiselev, V.S. (2004) “Arabeski” N.V. Gogolya i traditsii romanticheskoy tsiklizatsii [Arabesques by N.V. Gogol and traditions of romantic cyclization]. Izvestiya Rossiyskoy akademii nauk. Seriya literatury i yazyka. 63:6. pp. 15-25.

42. Uzeneva, E.S. (2009) Posidelki [Evenings]. In: Tolstoy, N.I. (ed.) Slavyanskie drevnosti [Slavic antiquities]. Vol. 4. Moscow: Mezhdunarodnye otnosheniya.

43. Vinogradova, L.N. (2006) Sotsioregulyativnaya funktsiya suevernykh rasskazov o narushitelyakh zapretov i obychaev [The social and regulatory function of superstitious stories about offenders of prohibitions and customs]. In: Tolstaya, S.M. (ed.) Slavyanskiy $i$ balkanskiy fol'klor. Semantika i pragmatika teksta [Slavic and Balkan folklore. The semantics and pragmatics of the text]. Moscow: Indrik.

44. Bayburin, A.K. (2003) Okno v zvukovom prostranstve [The window in the sound space]. In: Ivanov, V.V. (ed.) Evraziyskoe prostranstvo: Zvuk, slovo, obraz [Eurasian space: sound, word, image]. Moscow: Yazyki sla-vyanskoy kul'tury. 